\title{
Ternary and Higher Order Aluminum Phase Diagram Updates
}

Ternary aluminum phase diagrams were compiled by ASM International (Handbook of Ternary Alloy Phase Diagrams, eds., P. Villars, A. Prince, and H. Okamoto, Volumes 3-4) and by VCH Verlagsgesellschaft, Germany (Ternary Alloys, eds., G. Petzow and G. Effenberg, Volumes 3-8). They cover the period from 1900 to 1990. A large number of new publications have appeared in the literature in the last 15 years. It is the purpose of this Addendum to review briefly the new information, using as the starting point either the data compiled in the ASM volumes or any other later evaluation.

Many of the phase equilibrium studies of Al-Ni-X and Al-Ni- $\mathrm{X}_{1}-\mathrm{X}_{2}$ systems have been in the $\mathrm{Ni}$-rich region, due to the technological importance of the nickel aluminides. NiAl $(\beta)$ has a low density, high melting temperature, and excellent oxidation resistance. $\mathrm{Ni}_{3} \mathrm{Al}\left(\gamma^{\prime}\right)$ has the unusual property of increasing strength with increasing temperature. In order to improve the other properties of nickel aluminides such as creep resistance and room temperature ductility, various additions are made to Al-Ni alloys and the corresponding phase diagrams have attracted a great deal of attention in recent years. This issue carries updates on eight Al-Ni-X (X: Co, Cr, Cu, La, Mo, Nb, $\mathrm{Nd}$, or Ta) ternary systems and on Al-Co-Cr-Ni, Al-Cr-Mo-Ni, Al-Cr-Ni-Ta, Al-Cr-Ni-W, Al-Mo$\mathrm{Ni}-\mathrm{Ta}$, and $\mathrm{Al}-\mathrm{Ni}-\mathrm{Ta}-\mathrm{V}$ quaternary systems. Updates on Al-Ni-Ti and $\mathrm{Al}-\mathrm{Ni}-\mathrm{V}$ ternary systems and on Al-Co-Ni-Ti, Al-Cr-Ni-Ti, Al-Cu-Ni-Ti, Al-Mn-Ni-Ti, Al-Nb-Ni-Ti, and Al-Ni-Ti-V systems have appeared in the earlier issues of this journal.

This work was supported by the Indian Institute of Metals, Calcutta.

\author{
V. Raghavan \\ Editor \\ Phase Diagrams of Ternary Iron Alloys
}

Parts 1, 2, 3, 5, and 6 